\title{
Optimizing psychosocial interventions in first-episode psychosis: current perspectives and future directions
}

This article was published in the following Dove Press journal:

Psychology Research and Behavior Management

27 April 2017

Number of times this article has been viewed

\author{
Nicholas JK Breitborde ${ }^{1,2}$ \\ Aubrey M Moe' \\ Arielle Ered ${ }^{3}$ \\ Lauren M Ellman ${ }^{3}$ \\ Emily K Bell ${ }^{4}$
}

'Department of Psychiatry and Behavioral Health, ${ }^{2}$ Department of Psychology, The Ohio State University, Columbus, $\mathrm{OH},{ }^{3}$ Department of Psychology, Temple University, Philadelphia, PA, ${ }^{4}$ Department of Psychiatry, University of Arizona, Tucson, AZ, USA
Correspondence: Nicholas JK Breitborde Department of Psychiatry and Behavioral Health, The Ohio State University, 1670 Upham Dr., Columbus, OH 43210, USA $\mathrm{Tel}+\mathrm{I} 6 \mid 46856052$

Email nicholas.breitborde@osumc.edu

\begin{abstract}
Psychotic-spectrum disorders such as schizophrenia, schizoaffective disorder, and bipolar disorder with psychotic features are devastating illnesses accompanied by high levels of morbidity and mortality. Growing evidence suggests that outcomes for individuals with psychoticspectrum disorders can be meaningfully improved by increasing the quality of mental health care provided to these individuals and reducing the delay between the first onset of psychotic symptoms and the receipt of adequate psychiatric care. More specifically, multicomponent treatment packages that 1) simultaneously target multiple symptomatic and functional needs and 2) are provided as soon as possible following the initial onset of psychotic symptoms appear to have disproportionately positive effects on the course of psychotic-spectrum disorders. Yet, despite the benefit of multicomponent care for first-episode psychosis, clinical and functional outcomes among individuals with first-episode psychosis participating in such services are still suboptimal. Thus, the goal of this review is to highlight putative strategies to improve care for individuals with first-episode psychosis with specific attention to optimizing psychosocial interventions. To address this goal, we highlight four burgeoning areas of research with regard to optimization of psychosocial interventions for first-episode psychosis: 1) reducing the delay in receipt of evidence-based psychosocial treatments; 2) synergistic pairing of psychosocial interventions; 3 ) personalized delivery of psychosocial interventions; and 4) technological enhancement of psychosocial interventions. Future research on these topics has the potential to optimize the treatment response to evidence-based psychosocial interventions and to enhance the improved (but still suboptimal) treatment outcomes commonly experienced by individuals with first-episode psychosis.
\end{abstract}

Keywords: first-episode psychosis; multicomponent care; psychosocial treatment; personalized medicine

\section{Introduction}

Psychotic-spectrum disorders such as schizophrenia, schizoaffective disorder, and bipolar disorder with psychotic features are devastating illnesses accompanied by high levels of morbidity and mortality. Under usual systems of care, these disorders are characterized by repeated symptomatic relapses, ${ }^{1-3}$ elevated rates of psychiatric comorbidities such as anxiety, depressive, and substance use disorders, ${ }^{4,5}$ reduced rates of participation in competitive occupational and educational activities, ${ }^{6-8}$ severe deficits in cognitive abilities, ${ }^{9-11}$ rates of death by suicide up to 12 times greater than population norms, ${ }^{12,13}$ and a life expectancy reduced by up to 25 years ${ }^{14,15}$ due primarily to cardiovascular, infectious, and pulmonary diseases. ${ }^{13,16}$ The severity of these disorders was recently highlighted within the Global Burden of Disease (GBD) Study. ${ }^{17-19}$ As part 
of a larger effort to quantify the deleterious effects of various health conditions worldwide, the GBD Study assigns a disability weight to over 300 illnesses and injuries - a numerical value indicating where a particular health state exists on a range from 0 (i.e., a state of perfect health) to 1 (i.e., a health state equivalent to death). Within the two past iterations of the GBD study, the acute presentation of schizophrenia - the prototypical psychotic-spectrum disorder - where active hallucinations and delusions are present was assigned the highest disability weight among all illness and injuries. ${ }^{20,21}$ In fact, while achieving remission of hallucinations and delusions is often considered a "treatment success" for individuals with schizophrenia, ${ }^{22,23}$ this health state (i.e., schizophrenia in its residual state) was assigned the ninth highest disability weight among all illnesses and injuries in the GBD study. ${ }^{20,21}$ When a "successful" treatment outcome equates to the ninth worst health state that humans can experience other than death, there is significant room for improvement in existing treatments for a given disorder.

Growing evidence suggests that outcomes for individuals with psychotic-spectrum disorders can be meaningfully improved by increasing the quality of mental health care provided to these individuals and reducing the delay between the first onset of psychotic symptoms and the receipt of adequate psychiatric care. ${ }^{24,25}$ More specifically, multicomponent treatment packages that 1) simultaneously target multiple symptomatic and functional needs and 2) are provided as soon as possible following the initial onset of psychotic symptoms, appear to have disproportionately positive effects on the course of psychotic-spectrum disorders. ${ }^{26,27}$ To date, numerous trials of multicomponent treatment packages for individuals early in the course of a psychotic-spectrum disorder - a period frequently referred to as "first-episode psychosis" 28 - have been completed by independent research teams across four continents. Although there is some variation in the results, overall, these studies suggest that multicomponent care for first-episode psychosis may produce improved outcomes across numerous psychiatric (e.g., positive symptoms, negative symptoms, and depressive symptomatology) and functional domains (e.g., cognition, social functioning, and participation in competitive work and school). ${ }^{29-40}$ In response to these findings, multicomponent care provided as soon as possible following the first onset of psychotic symptoms is now recognized as the new "gold standard" in the treatment of psychotic-spectrum disorders. Such treatment programs are now available in every continent with the exception of Antarctica, ${ }^{41,42}$ and several countries have launched federallysupported efforts to disseminate multicomponent care for first-episode psychosis nationwide. ${ }^{43-45}$ For example, between fiscal year 2014 and 2016, the federal government of the USA dedicated nearly $\$ 100$ million to support the dissemination of Coordinated Specialty Care for first-episode psychosis - a multicomponent treatment program comprised of individual psychotherapy, family psychoeducation, medication management, and supported employment and education. ${ }^{46}$

A key contribution of the recent movement toward multicomponent treatment programs for first-episode psychosis is increased recognition of the value of psychosocial interventions for psychotic-spectrum disorders. Although existing treatment guidelines typically identify pharmacological treatment as the "cornerstone" or "first-line" treatment of psychotic-spectrum disorders, ${ }^{47-49}$ there is growing recognition that medication alone cannot fully ameliorate the morbidity and mortality associated with these disorders. ${ }^{50-53}$ For example, while antipsychotic medications have clear efficacy with regard to the treatment of psychotic symptomatology, ${ }^{54,55}$ available evidence suggests that such symptoms may account for $<1 \%$ of the illness-related disability experienced by individuals with firstepisode psychosis (Moe and Breitborde, unpublished data, 2017). Effects of antipsychotic medication on other meaningful outcomes in psychotic-spectrum disorders (e.g., employment, cognition, and social functioning) are small and may not be clinically significant. ${ }^{11,51,56,57}$ Current multicomponent treatment programs for first-episode psychosis emphasize a combination of psychosocial and pharmacological interventions as first-line treatment $^{58,59}$ and available data have demonstrated that such combined treatment produces improved outcomes among individuals with psychotic-spectrum disorders - including firstepisode psychosis - when compared with medication alone. ${ }^{60-62}$

Yet, despite the benefit of multicomponent care for firstepisode psychosis, clinical and functional outcomes among individuals participating in such services are still suboptimal. ${ }^{26,63,64}$ Among such individuals, inpatient psychiatric hospitalizations are common, ${ }^{31}$ substance use - especially tobacco - is high, ${ }^{29}$ poor physical health outcomes are the norm, ${ }^{65}$ and rates of participation in competitive employment remain lower than their age-matched peers without psychotic-spectrum disorders. ${ }^{30}$ Consequently, there is still significant room for improvement in the treatment of firstepisode psychosis. ${ }^{26,63}$

Thus, the goal of this review is to highlight putative strategies to improve care for individuals with first-episode psychosis with specific attention to optimizing psychosocial interventions. To address this goal, we highlight several optimization strategies with the potential to enhance the benefits associated with these interventions. In particular, we focus our review on burgeoning areas of research with regard to optimization of psychosocial interventions for first-episode 
psychosis and avoid reviewing strategies that are already clearly documented elsewhere (e.g., building a strong therapeutic alliance ${ }^{66}$ and addressing the comorbid psychiatric symptoms, functional deficits, and cognitive decline that accompany first-episode psychosis ${ }^{67-73}$ ).

\section{Strategy I: reduce the delay in receipt of evidence-based psychosocial treatments}

Within the first-episode psychosis literature, there is a clear association between the duration of untreated psychosis (DUP; i.e., the time between the first onset of psychotic symptoms and the receipt of adequate mental health care) and the course of psychotic-spectrum disorders. More specifically, a longer DUP is associated with a worse course of illness and poorer response to treatment. ${ }^{25,31,32,74}$ Many studies have defined the endpoint of the DUP (i.e., the receipt of adequate mental health care) as participation in some duration of antipsychotic medication. ${ }^{75,76}$ However, time until the start of evidence-based psychosocial interventions may also be an important endpoint following the first onset of psychotic symptoms. For example, in a seminal paper, de Haan et $a l^{76}$ examined the association between the duration of time between the first onset of psychotic symptoms and the first receipt of intensive psychosocial treatment (i.e., delay in intensive psychosocial treatment [DIPT]) and the course of schizophrenia. Given the limited availability of evidencebased psychosocial treatments for psychosis in usual care settings, ${ }^{77}$ it is not surprising that de Haan et al found that the mean DIPT (19 months) was nearly twice as long as the mean DUP (8.6 months). Among their sample, there were positive univariate associations between negative symptoms at 6-year follow-up and both DUP and DIPT (i.e., greater negative symptoms associated with longer DUP and DIPT, respectively). However, in multivariate analyses simultaneously examining DUP and DIPT, only DIPT was found to be a statistically significant predictor of negative symptoms at 6-year follow-up. These results raise the possibility that reducing the delay between the first onset of psychotic symptoms and the receipt of evidence-based psychosocial care may be a modifiable risk factor through which providers can improve the course of psychotic-spectrum disorders. This hypothesis comports with data suggesting that individuals earlier in the course of psychotic-spectrum disorders have a greater response to psychosocial treatments when compared with individuals with more longstanding illnesses. ${ }^{78-80}$

Despite the potential importance of DIPT to the course of psychotic-spectrum disorders, we are unaware of any subsequent studies that have investigated this concept in the
13 years since the paper by de Haan et al. ${ }^{76}$ Consequently, there is a great utility for additional research to clarify the association between delay in access to psychosocial treatments and the course of psychotic-spectrum disorders. In addition, psychiatric service research may benefit from examining how evidence-based psychosocial services can be incorporated within inpatient psychiatric settings. Although the inpatient psychiatric unit is often the first care setting for individuals with first-episode psychosis ${ }^{81}$ evidence-based psychosocial treatments for first-episode psychosis are typically available in outpatient settings only. Thus, incorporating specialized psychosocial treatments in inpatient settings may be an important strategy in reducing delay of appropriate psychosocial care.

\section{Strategy 2: synergistic pairing of psychosocial interventions}

Kern et $\mathrm{al}^{62}$ have highlighted that although numerous evidence-based psychosocial interventions are available for psychotic-spectrum disorders, no single psychosocial intervention is sufficient to address numerous health and functional consequences associated with these disorders Thus, there is growing interest in examining how best to pair psychosocial interventions to improve outcomes among individuals with first-episode psychosis. Although research in this area is still developing, promising results from the broader literature on psychotic-spectrum disorders are already available with regard to effective pairing of psychosocial interventions with cognitive remediation - an intervention defined by the 2010 Cognitive Remediation Experts Workshop as "a behavioral training based intervention that aims to improve cognitive processes (attention, memory, executive function, social cognition, or metacognition) with the goal of durability and generalization." To date, studies have examined the benefits of pairing cognitive remediation with several additional psychosocial interventions, including work therapy and supported employment programs, ${ }^{82-84}$ functional skills training, ${ }^{85}$ and even an aerobic exercise program. ${ }^{86}$

Bell et a ${ }^{82}$ examined a combined cognitive remediation and work therapy program, which involved individuals with schizophrenia or schizoaffective disorder being randomly assigned to receive cognitive remediation - characterized by completion of computerized cognitive exercises and weekly processing groups - plus work therapy or work therapy alone for 6 months. Although both groups showed improvements, individuals in the cognitive remediation and work therapy group evidenced greater mean differences and larger effectsize changes on cognitive performance, including working memory, attention, and executive functioning. An additional 
study by the same group ${ }^{83}$ using the same methodology but with an extended treatment period of 1 year similarly revealed that individuals who received combined cognitive remediation and work therapy had significantly better performance on measures of executive functioning and working memory post-treatment compared with those who received work therapy alone. In a sample of 44 individuals with schizophrenia, McGurk et al ${ }^{84}$ compared the effects of 12 weeks of supported employment and computerized cognitive training against supported employment alone. Post-treatment cognitive testing revealed that those in the combined cognitive training plus supported employed group performed significantly better on an overall composite cognition score than those receiving supported employment alone, and that these individuals in the combined condition also showed significant reduction in depression and autistic preoccupation and better work outcomes compared with individuals in the supported employment-alone condition. The functional outcome improvements, particularly in work functioning, can be directly attributed to the addition of cognitive remediation in this case, as all other aspects of treatment were matched. Although work training and supported employment programs target work functioning directly, the addition of cognitive training led to greater levels of employment, more hours worked, and better functioning at work in individuals with schizophrenia. In addition, those receiving cognitive remediation also showed improvement in other domains (i.e., symptom levels and neurocognitive functioning).

In an additional study, Bowie et a ${ }^{85}$ randomly assigned individuals with schizophrenia to receive cognitive remediation, functional adaptation skills training, or a combination of both treatments. Although improvements in neurocognition were observed in both the cognitive training and combined treatment groups and social competence significantly improved in the functional skills and combined treatment group, the combined treatment group showed significantly greater improvements in functional competence and realworld community activities than either the functional skills training and cognitive remediation-only groups. Importantly, the durability of these gains was greatest in the combined treatment group. Taken together, these results suggest that a combined treatment approach may produce better gains across domains that are more likely to persist over time.

The utility of combining cognitive remediation and physical activity has also been explored. In a recently published pilot study, ${ }^{86}$ individuals early in the course of a schizophrenia-spectrum disorder were randomly assigned to 10 weeks of either cognitive training alone or cognitive training combined with aerobic exercise sessions. Even with a small sample and short training period, individuals receiving combined cognitive training and exercise demonstrated larger gains in overall cognitive abilities compared with participants receiving cognitive training alone. These preliminary data suggest that a combination approach including both exercise and cognitive remediation allows for even larger gains in cognition than cognitive remediation alone.

Thus, research on cognitive remediation has highlighted strategies to increase the size, breadth, and durability of treatment effects via the deliberate pairing of psychosocial interventions. These findings are especially relevant to the treatment of first-episode psychosis given the improved, but still suboptimal benefits associated with current multicomponent treatment programs ${ }^{64}$ and questions about the durability of these benefits after discharge from such multicomponent treatment programs..$^{87,88}$ Moreover, within most multicomponent treatment for first-episode psychosis, decisions with regard to psychosocial intervention uptake are typically individual preferences of providers and individuals with first-episode psychosis. Although such preferences are valuable - especially those of individuals with first-episode psychosis - future research exploring how specific psychosocial interventions can be synergistically paired may enhance clinical outcomes among individuals participating in multicomponent care for first-episode psychosis.

\section{Strategy 3: personalized delivery of psychosocial interventions}

Within the larger psychiatric literature, there is significant interest in advancing personalized medicine ${ }^{89}$ - "the prescription of specific treatments and therapeutics best suited for an individual taking into consideration both genetic and environmental factors that influence response to therapy" ${ }^{90}$ The treatment decisions resulting from these considerations fall under the categories of "macrotreatment" and "microtreatment" decisions. ${ }^{91}$ Macrotreatment decisions are those that guide selection of specific interventions, whereas microtreatment decisions guide the delivery of specific aspects of an intervention. Given the heterogeneous presentation and course of psychotic-spectrum disorder, ${ }^{92-94}$ personalized prescription of psychosocial intervention may help to maximize treatment outcomes among individuals with first-episode psychosis.

In recent years, there has been increasing focus on research suggesting that genetic variants associated with psychosis can be used to guide antipsychotic medication management decisions. ${ }^{95}$ Genetic variants could also potentially be used to guide macrotreatment decisions concerning which psychosocial interventions are prescribed to specific individuals with first-episode psychosis. For example, growing 
research has considered whether an individual's response to cognitive remediation may be moderated by genetic factors. To date, several studies have examined whether response to cognitive remediation may be predicted by the catechol-Omethyltransferase (COMT) gene via its putative influence on prefrontal dopamine functioning. ${ }^{96-98}$ However, results from these studies are equivocal. There is some evidence that response to cognitive remediation among individuals with first-episode psychosis may be influenced by the expression of genes involved in memory and synaptic plasticity (e.g., activity-regulated cytoskeleton-associated protein [ARC]). In one recent study, ${ }^{99}$ individuals identified as carriers of the ARC T allele showed significant improvement in overall cognitive functioning after participating in metacognitive remediation therapy, whereas non-T-carriers did not.

Another potential characteristic that could be used to personalize psychosocial intervention prescription for individuals with first-episode psychosis is personality traits. It has been demonstrated that non-pathological personality traits are associated with course of illnesss and subjective experiences of symptoms in individuals with psychosis, ${ }^{100}$ as well as other relevant correlates of psychotic-spectrum disorders such as social cognitive abilities. ${ }^{101} \mathrm{~A}$ framework for considering both research and theory of personality in first-episode psychosis intervention decisions has been proposed $^{102}$ that would first involve formal assessment of personality characteristics. These assessment data could then be used to inform macrotreatment decisions, such as choice of intervention formats (e.g., group interventions, caregiver involvement) and microtreatment decisions, such as how to tailor interventions for specific individuals to best address their unique symptomatology, functional deficits, and treatment goals.

Finally, the typical emergence of psychotic symptoms in the late teens to early $20{ }^{\prime}{ }^{103}$ raises the possibility that psychosocial interventions for first-episode psychosis may be enhanced by tailoring them to the unique needs of individuals in this developmental stage. In his seminal writings, Arnett has referred to this developmental stage as "emerging adulthood" and has described it as "a period characterized by change and exploration for most people, as they examine the life possibilities open to them and gradually arrive at more enduring choices in love, work, and worldviews." 104 Drawing on this research, McGorry et al have advocated for the development of youth-friendly mental health services that promote shared decision-making in treatment and emphasize social and vocational outcomes (as opposed to symptomatic remission) as key treatment goals. ${ }^{105,106}$ Such characteristics are not only consistent with the norms of this developmental stage (e.g., movement toward greater autonomy and establishing the foundation for longstanding vocational and relationship roles) but may also play a role in whether emerging adults access and remain engaged in specialized services for first-episode psychosis. ${ }^{105}$ For example, early evidence from existing youth-friendly mental health services suggests that they may be successful in increasing rates of youth and young adults from traditionally underserved populations who choose to access mental health services. ${ }^{107,108}$

\section{Strategy 4: technological enhancement of psychosocial interventions}

Another promising avenue for optimization of psychosocial treatment for first-episode psychosis involves integration of technological advances. Although clinical research has benefitted for several decades from emerging imaging and psychophysiological measurement technologies, these advancements are increasingly proliferated into people's typical, everyday activities (e.g., smartphones, digital streaming technologies, and fitness trackers equipped with heart-rate monitors). As these technologies continually interface with normative human activities, they represent an important avenue for advancement and expansion of health care and treatment. Interventions delivered via technology or technology-enhanced treatment may be a cost-effective way to provide personalized, flexible, and evidence-based interventions directly to individuals in their communities or homes. ${ }^{109}$ The use of technology-enhanced treatment has a myriad of potential clinical benefits for individuals with first-episode psychosis, including the capability of providing real-time cues to engage in particular behaviors as a compensatory mechanism for memory deficits (e.g., to encourage medication adherence ${ }^{110}$ ), as well as the ability to alert individuals to physiological early warning signs of symptomatic exacerbations in a personalized manner (e.g., changes in heart-rate variability ${ }^{111}$ ).

Although the use of technological advancements in psychiatric treatment is in its relative infancy, ${ }^{112}$ the ready availability and sophistication of these technologies is promising. This has been particularly true for smartphones and apps, which represent one of the most rapidly expanding and adopted forms of technology in human history. ${ }^{113}$ Available research suggests that up to $90 \%$ of individuals with firstepisode psychosis have access to smartphones. ${ }^{114,115}$ Given the wide availability of this technology, these devices are ideal for assessment of in vivo experiences of individuals with psychosis. Ecological momentary assessment (EMA) - a method for collecting information on naturalistic behaviors 
and experiences that has previously been done with paperand-pencil methodology - has been enhanced by the use of smartphones. Smartphones offer participants the opportunity to record information about their symptoms, feelings, and thoughts in an immediately accessible forum that can automatically sync with an external database. This approach can mitigate the impact of cognitive deficits on memory and recall, and can also provide cues for individuals to engage in reflecting on internal processes and recording information that can minimize the impact of deficits in the initiation of behaviors that accompany psychotic-spectrum disorders. Further, research suggests that symptom ratings collected from individuals with psychosis via smartphone technology have greater concordance with clinician ratings compared with self-ratings made with paper and pencil. ${ }^{116}$ In addition to being used to enhance treatment via self-monitoring, smartphone technology can also be used to deliver interventions directly to individuals with psychosis. Ben-Zeev et al ${ }^{117}$ recently investigated the efficacy of a smartphone-based treatment to people with schizophrenia. This intervention was designed to provide automated real-time/real-place illness management support to individuals and was found to produce improvements in mood regulation, medication adherence, social functioning, and sleep. The demonstrated feasibility, acceptability, and preliminary efficacy of this smartphone intervention for schizophrenia offer promise for extending evidence-based treatment for first-episode psychosis beyond physical clinics and into the literal pockets of individuals via widely available smartphone technology. As the benefits of specialized care for first-episode psychosis may disappear when young adults return to usual care ${ }^{87,88}$ the extension of evidence-based psychosocial treatment via smartphone technology could potentially be leveraged to increase the durability of the benefits produced by such specialized, but typically time-limited, care.

Of note, the possibilities for integration of technology into psychosocial treatment for first-episode psychosis also extend to social media more broadly. For example, Alvarez-Jimenez et $\mathrm{al}^{118}$ developed HORYZONS, an online intervention specifically for youth with first-episode psychosis. Individuals with first-episode psychosis could engage in a variety of interactive psychosocial interventions on this moderated forum and were also able to engage in peer-to-peer social networking. Results indicated that this approach was feasible, engaging, and safe for participants. The use of online forums to enhance other psychosocial treatments for first-episode psychosis is especially attractive, given its cost-effective nature, as well as its potential to provide ongoing support that may prevent disengagement from clinical services.
Technological advances are an evolving and exciting area for clinical service delivery. However, the importance of an evidence-based approach to treatment should not be forgotten. Thus, there is a great need for additional research of smartphone and other technology enhancements for first-episode psychosis. In the interim, mental health providers should strive to be both open-minded and prudent in the integration of technology into treatment for first-episode psychosis. Although many mental health apps are currently available, the vast majority have not been scientifically evaluated. ${ }^{112,119}$ However, the literature on the use of apps for clinical treatment of psychotic-spectrum disorders - despite being limited - does provide strong evidence for the feasibility of this approach as well as high rates of patient engagement and interaction. ${ }^{120}$

\section{Conclusion}

Outside of the first-episode psychosis literature, Guralnick ${ }^{121}$ has highlighted the distinction between first-generation and second-generation research - research designed to investigate the efficacy/effectiveness of an intervention versus research designed to investigate how to optimize outcomes associated with a proven intervention. With the efficacy and effectiveness of numerous psychosocial interventions for first-episode psychosis clearly established, scholars have noted the growing need for a shift toward second-generation research within the field. ${ }^{122}$ The optimization strategies described above highlight some of the increasing corpus of second-generation research on the treatment of first-episode psychosis that is emerging internationally. Ultimately, such research has the potential to optimize the treatment response to evidence-based psychosocial interventions and to enhance the improved (but still suboptimal) treatment outcomes commonly experienced by individuals with first-episode psychosis. Moreover, as interest in intervention for psychosis before the first-episode grows, ${ }^{123,124}$ continued research on the optimization of psychosocial interventions may also highlight ways to improve the prevention of psychotic disorders among those at clinical high risk.

\section{Disclosure}

Drs Breitborde and Moe have both received salary support from the Institute for Mental Health Research (IMHR) to support the launch of IMHR's new clinical service for individuals with first-episode psychosis. They also received salary support from the Ohio Department of Mental Health and Addiction Services to support the launch of a new clinical service for individuals with first-episode psychosis in Fairfield County, Ohio. This project was supported by funds provided by The Ohio State University Department of 
Psychiatry and Mental Health to Dr Breitborde. The authors report no other conflicts of interest in this work.

\section{References}

1. Thara R, Henrietta M, Joseph A, Rajkumar S, Eaton W. Ten-year course of schizophrenia - the Madras longitudinal study. Acta Psychiatr Scand. 1994;90(5):329-336

2. Alvarez-Jimenez M, Priede A, Hetrick S, et al. Risk factors for relapse following treatment for first episode psychosis: a systematic review and meta-analysis of longitudinal studies. Schizophr Res. 2012; 139(1-3):116-128.

3. Wiersma D, Nienhuis FJ, Slooff CJ, Giel R. Natural course of schizophrenic disorders: a 15-year followup of a Dutch incidence cohort. Schizophr Bull. 1998;24(1):75-85.

4. Buckley PF, Miller BJ, Lehrer DS, Castle DJ. Psychiatric comorbidities and schizophrenia. Schizophr Bull. 2009;35(2):383-402.

5. Morgan VA, Waterreus A, Jablensky A, et al. People living with psychotic illness in 2010: the second Australian national survey of psychosis. Aust N Z J Psychiatry. 2012;46(8):735-752.

6. Marwaha S, Johnson S. Schizophrenia and employment. Soc Psychiatry Psychiatr Epidemiol. 2004;39(5):337-349.

7. Rosenheck R, Leslie D, Keefe R, et al. Barriers to employment for people with schizophrenia. Am J Psychiatry. 2006;163(3):411-417.

8. Waghorn G, Saha S, Harvey C, et al. 'Earning and learning' in those with psychotic disorders: the second Australian national survey of psychosis. Aust N Z J Psychiatry. 2012;46(8):774-785.

9. Fioravanti M, Carlone O, Vitale B, Cinti ME, Clare L. A meta-analysis of cognitive deficits in adults with a diagnosis of schizophrenia. Neuropsychol Rev. 2005;15(2):73-95.

10. Lewandowski K, Cohen B, Öngur D. Evolution of neuropsychological dysfunction during the course of schizophrenia and bipolar disorder. Psychol Med. 2011;41(2):225-241.

11. Breitborde NJK, Meier M. Cognition in first-episode psychosis: from phenomenology to intervention. Clin Psychiatry Rev. 2016; 12(4):306-318.

12. Dutta R, Murray RM, Hotopf M, Allardyce J, Jones PB, Boydell J. Reassessing the long-term risk of suicide after a first episode of psychosis. Arch Gen Psychiatry. 2010;67(12):1230-1237.

13. Dutta R, Murray R, Allardyce J, Jones P, Boydell J. Mortality in firstcontact psychosis patients in the UK: a cohort study. Psychol Med. 2012; 42(08):1649-1661.

14. Laursen TM, Munk-Olsen T, Vestergaard M. Life expectancy and cardiovascular mortality in persons with schizophrenia. Curr Opin Psychiatry. 2012;25(2):83-88.

15. Laursen TM, Nordentoft M, Mortensen PB. Excess early mortality in schizophrenia. Annu Rev Clin Psychol. 2014;10:425-448.

16. Shiers D, Jones PB, Field S. Early intervention in psychosis: keeping the body in mind. Br J Gen Pract. 2009;59(563):395-396.

17. Murray CJ, Lopez AD. Global mortality, disability, and the contribution of risk factors: Global Burden of Disease Study. Lancet. 1997;349(9063):1436-1442.

18. Murray CJ, Lopez AD. Evidence-based health policy--lessons from the Global Burden of Disease Study. Science. 1996;274(5288):740.

19. Murray CJL, Lopez AD. The Global Burden of Disease. Boston: Harvard University Press; 1996.

20. Salomon JA, Haagsma JA, Davis A, et al. Disability weights for the Global Burden of Disease 2013 study. Lancet Glob Health. 2015; 3(11):e712-e723.

21. Salomon JA, Vos T, Hogan DR, et al. Common values in assessing health outcomes from disease and injury: disability weights measurement study for the Global Burden of Disease Study 2010. Lancet. 2013; 380(9859):2129-2143.

22. Lipkovich IA, Deberdt W, Csernansky JG, et al. Defining "good" and "poor" outcomes in patients with schizophrenia or schizoaffective disorder: a multidimensional data-driven approach. Psychiatry Res. 2009; 170(2):161-167.
23. Andreasen NC, Carpenter Jr WT, Kane JM, Lasser RA, Marder SR, Weinberger DR. Remission in schizophrenia: proposed criteria and rationale for consensus. Am J Psychiatry. 2005;162(3):441-449.

24. Marshall M, Lewis S, Lockwood A, Drake R, Jones P, Croudace T. Association between duration of untreated psychosis and outcome in cohorts of first-episode patients: a systematic review. Arch Gen Psychiatry. 2005;62(9):975-983.

25. Perkins DO, Gu H, Boteva K, Lieberman JA. Relationship between duration of untreated psychosis and outcome in first-episode schizophrenia: a critical review and meta-analysis. Am J Psychiatry. 2005;162(10): 1785-1804.

26. Breitborde NJK, Moe AM. Early intervention in psychosis in the United States: From science to policy reform. Policy Insights Brain Behav Sci. 2016;4(1):79-87.

27. Srihari VH, Shah J, Keshavan MS. Is early intervention for psychosis feasible and effective? Psychiat Clin NAm. 2012;35(3):613-631.

28. Breitborde NJK, Srihari VH, Woods SW. Review of the operational definition for first-episode psychosis. Early Interv Psychiatry. 2009; 3(4):259-265.

29. Breitborde NJK, Bell EK, Dawley D, et al. The Early Psychosis Intervention Center (EPICENTER): development and six-month outcomes of an American first-episode psychosis clinical service. BMC Psychiatry. 2015;15:266.

30. Srihari VH, Tek C, Kucukgoncu S, et al. First-episode services for psychotic disorders in the US public sector: a pragmatic randomized controlled trial. Psychiatr Serv. 2015;66(7):705-712.

31. Kane JM, Robinson DG, Schooler NR, et al. Comprehensive versus usual community care for first-episode psychosis: 2-year outcomes from the NIMH RAISE early treatment program. Am J Psychiatry. 2016;173(4):362-372.

32. Rosenheck R, Mueser KT, Sint K, et al. Supported employment and education in comprehensive, integrated care for first episode psychosis: effects on work, school, and disability income. Schizophr Res. 2017;182:120-128.

33. Ruggeri M, Bonetto C, Lasalvia A, et al. Feasibility and effectiveness of a multi-element psychosocial intervention for first-episode psychosis: results from the cluster-randomized controlled GET UP PIANO trial in a catchment area of 10 million inhabitants. Schizophr Bull. 2015;41(5):1192-1203.

34. Kuipers E, Holloway F, Rabe-Hesketh S, Tennakoon L. An RCT of early intervention in psychosis: Croydon Outreach and Assertive Support Team (COAST). Soc Psychiatry Psychiatr Epidemiol. 2004;39(5):358-363.

35. McGorry PD, Edwards J, Mihalopoulos C, Harrigan SM, Jackson HJ. EPPIC: an evolving system of early detection and optimal management. Schizophr Bull. 1996;22(2):305-326.

36. Craig TK, Garety P, Power P, et al. The Lambeth Early Onset (LEO) Team: randomised controlled trial of the effectiveness of specialised care for early psychosis. BMJ. 2004;329(7474):1067-1070.

37. Petersen L, Jeppesen $P$, Thorup A, et al. A randomised multicentre trial of integrated versus standard treatment for patients with a first episode of psychotic illness. BMJ. 2005;331(7517):602.

38. Chen EY, Tang JY, Hui CL, et al. Three-year outcome of phase-specific early intervention for first-episode psychosis: a cohort study in Hong Kong. Early Interv Psychiatry. 2011;5(4):315-323.

39. Uzenoff SR, Penn DL, Graham KA, Saade S, Smith BB, Perkins DO. Evaluation of a multi-element treatment center for early psychosis in the United States. Soc Psychiatry Psychiatr Epidemiol. 2012;47(10):1607-1615.

40. Hegelstad WT, Larsen TK, Auestad B, et al. Long-term follow-up of the TIPS early detection in psychosis study: effects on 10-year outcome. Am J Psychiatry. 2012;169(4):374-380.

41. Reading B, Birchwood M. Early intervention in psychosis: rationale and evidence for effectiveness. Dis Manag Health Out. 2005;13:53-63.

42. Jorge Rde C, Chaves AC. The experience of caregiving inventory for first-episode psychosis caregivers: validation of the Brazilian version. Schizophr Res. 2012;138(2-3):274-279.

43. Nordentoft M, Melau M, Iversen T, et al. From research to practice: how OPUS treatment was accepted and implemented throughout Denmark. Early Interv Psychiatry. 2015;9(2):156-162. 
44. Joseph R, Birchwood M. The national policy reforms for mental health services and the story of early intervention services in the United Kingdom. J Psychiatry Neurosci. 2005;30(5):362-365.

45. Hughes F, Stavely H, Simpson R, Goldstone S, Pennell K, McGorry P. At the heart of an early psychosis centre: the core components of the 2014 early psychosis prevention and intervention centre model for Australian communities. Australas Psychiatry. 2014;22(3):228-234.

46. Azrin ST, Goldstein AB, Heinssen RK. Expansion of coordinated specialty care for first-episode psychosis in the US. Focal Point. 2016; 30:9-11.

47. Hasan A, Falkai P, Wobrock T, et al. World Federation of Societies of Biological Psychiatry (WFSBP) Guidelines for Biological Treatment of Schizophrenia, Part 1: update 2012 on the acute treatment of schizophrenia and the management of treatment resistance. World $J$ Biol Psychiatry. 2012;13(5):318-378.

48. Galletly C, Castle D, Dark F, et al. Royal Australian and New Zealand college of psychiatrists clinical practice guidelines for the management of schizophrenia and related disorders. Aust N Z J Psychiatry. 2016; 50(5):410-472.

49. Kreyenbuhl J, Buchanan RW, Dickerson FB, Dixon LB. The schizophrenia patient outcomes research team (PORT): updated treatment recommendations 2009. Schizophr Bull. 2010;36(1):94-103.

50. Hogarty GE, Ulrich RF. The limited effects of antipsychotic medication on schizophrenia relapse and adjustment and the contributions of psychosocial treatment. J Psychiatr Res. 1998;32(3):243-250.

51. Goldberg TE, Goldman RS, Burdick KE, et al. Cognitive improvement after treatment with second-generation antipsychotic medications in first-episode schizophrenia: is it a practice effect? Arch Gen Psychiatry. 2007;64(10):1115-1122.

52. Swartz MS, Perkins DO, Stroup TS, et al. Effects of antipsychotic medications on psychosocial functioning in patients with chronic schizophrenia: findings from the NIMH CATIE study. Am J Psychiatry. 2007;164(3):428-436.

53. Weinmann S, Read J, Aderhold V. Influence of antipsychotics on mortality in schizophrenia: systematic review. Schizophr Res. 2009;113(1):1-11.

54. Leucht S, Cipriani A, Spineli L, et al. Comparative efficacy and tolerability of 15 antipsychotic drugs in schizophrenia: a multiple-treatments meta-analysis. Lancet. 2013;382(9896):951-962.

55. Leucht S, Arbter D, Engel R, Kissling W, Davis JM. How effective are second-generation antipsychotic drugs? A meta-analysis of placebocontrolled trials. Mol Psychiatry. 2009;14(4):429-447.

56. Leucht S, Tardy M, Komossa K, et al. Antipsychotic drugs versus placebo for relapse prevention in schizophrenia: a systematic review and meta-analysis. Lancet. 2012;379(9831):2063-2071.

57. Swartz MS, Perkins DO, Stroup TS, et al. Effects of antipsychotic medications on psychosocial functioning in patients with chronic schizophrenia: findings from the NIMH CATIE study. Am J Psychiatry. 2007;164(3):428-436

58. Mueser KT, Penn DL, Addington J, et al. The NAVIGATE program for first-episode psychosis: rationale, overview, and description of psychosocial components. Psychiatr Serv. 2015;66(7):680-690.

59. Dixon LB, Goldman HH, Bennett ME, et al. Implementing coordinated specialty care for early psychosis: the RAISE connection program. Psychiatr Serv. 2015;66(7):691-698.

60. Guo X, Zhai J, Liu Z, et al. Effect of antipsychotic medication alone vs combined with psychosocial intervention on outcomes of earlystage schizophrenia: a randomized, 1-year study. Arch Gen Psychiatry. 2010;67(9):895-904.

61. Lee SH, Choi TK, Suh S, et al. Effectiveness of a psychosocial intervention for relapse prevention in patients with schizophrenia receiving risperidone via long-acting injection. Psychiatry Res. 2010; 175(3): 195-199.

62. Kern RS, Glynn SM, Horan WP, Marder SR. Psychosocial treatments to promote functional recovery in schizophrenia. Schizophr Bull. 2009;35(2):347-361.

63. Breitborde NJK. First-episode psychosis: from phenomenology to intervention. Clin Psychiatry Rev. 2016;12(4):304-305.
64. McGrath JJ. The early intervention debate provides a distraction from another 'unspeakable truth'. Aust NZJ Psychiatry. 2012;46(7):681-682.

65. Srihari VH, Phutane VH, Ozkan B, et al. Cardiovascular mortality in schizophrenia: defining a critical period for prevention. Schizophr Res. 2013;146(1-3):64-68.

66. Frank AF, Gunderson JG. The role of the therapeutic alliance in the treatment of schizophrenia: relationship to course and outcome. Arch Gen Psychiatry. 1990;47(3):228-236.

67. Penn DL, Waldheter EJ, Perkins DO, Mueser KT, Lieberman JA. Psychosocial treatment for first-episode psychosis: a research update. $\mathrm{Am}$ J Psychiatry. 2005;162(12):2220-2220.

68. Ramsay CE, Broussard B, Goulding SM, et al. Life and treatment goals of individuals hospitalized for first-episode nonaffective psychosis. Psychiatry Res. 2011;189(3):344-348.

69. Birchwood M. Pathways to emotional dysfunction in first-episode psychosis. Br J Psychiatry. 2003;182(5):373-375.

70. Breitborde NJ, Moreno FA, Mai-Dixon N, et al. Multifamily group psychoeducation and cognitive remediation for first-episode psychosis: a randomized controlled trial. BMC Psychiatry. 2011;11:9.

71. Vesterager L, Christensen TØ, Olsen BB, et al. Cognitive training plus a comprehensive psychosocial programme (OPUS) versus the comprehensive psychosocial programme alone for patients with first-episode schizophrenia (the NEUROCOM trial): a study protocol for a centrally randomised, observer-blinded multi-centre clinical trial. Trials. 2011;12(1):35.

72. Mueser KT, Lu W, Rosenberg SD, Wolfe R. The trauma of psychosis: posttraumatic stress disorder and recent onset psychosis. Schizophr Res. 2010;116(2):217-227.

73. Killackey EJ, Jackson HJ, Gleeson J, Hickie IB, McGorry PD. Exciting career opportunity beckons! Early intervention and vocational rehabilitation in first-episode psychosis: employing cautious optimism. Aust $N$ ZJ Psychiatry. 2006;40(11-12):951-962.

74. Marshall M, Lewis S, Lockwood A, Drake R, Jones P, Croudace T. Association between duration of untreated psychosis and outcome in cohorts of first-episode patients: a systematic review. Arch Gen Psychiatry. 2005;62(9):975-983.

75. Compton MT, Carter T, Bergner E, et al. Defining, operationalizing and measuring the duration of untreated psychosis: advances, limitations and future directions. Early Interv Psychiatry. 2007;1(3):236-250.

76. de Haan L, Linszen DH, Lenior ME, de Win ED, Gorsira R. Duration of untreated psychosis and outcome of schizophrenia: delay in intensive psychosocial treatment versus delay in treatment with antipsychotic medication. Schizophr Bull. 2003;29(2):341-348.

77. Drake RE, Essock SM. The science-to-service gap in real-world schizophrenia treatment: the 95\% problem. Schizophr Bull. 2009;35(4): 677-678.

78. Bowie CR, Grossman M, Gupta M, Oyewumi L, Harvey PD. Cognitive remediation in schizophrenia: efficacy and effectiveness in patients with early versus long-term course of illness. Early Interv Psychiatry. 2014;8(1):32-38.

79. McFarlane WR. Multifamily Groups in the Treatment of Severe Psychiatric Disorders. New York, NY: Guilford; 2002.

80. Goldstein MJ. Psycho-education and family treatment related to the phase of a psychotic disorder. Int Clin Psychopharmacol. 1996;11(suppl 2): $77-83$.

81. Anderson K, Fuhrer R, Malla A. The pathways to mental health care of first-episode psychosis patients: a systematic review. Psychol Med. 2010;40(10):1585-1597.

82. Bell M, Bryson G, Greig T, Corcoran C, Wexler BE. Neurocognitive enhancement therapy with work therapy: effects on neuropsychological test performance. Arch Gen Psychiatry. 2001;58(8):763-768.

83. Greig TC, Zito W, Wexler BE, Fiszdon J, Bell MD. Improved cognitive function in schizophrenia after one year of cognitive training and vocational services. Schizophr Res. 2007;96(1):156-161.

84. McGurk SR, Mueser KT, Pascaris A. Cognitive training and supported employment for persons with severe mental illness: one-year results from a randomized controlled trial. Schizophr Bull. 2005;31(4): 898-909. 
85. Bowie CR, McGurk SR, Mausbach B, Patterson TL, Harvey PD. Combined cognitive remediation and functional skills training for schizophrenia: effects on cognition, functional competence, and realworld behavior. Am J Psychiatry. 2012;169(7):710-718.

86. Nuechterlein KH, Ventura J, McEwen SC, Gretchen-Doorly D, Vinogradov S, Subotnik KL. Enhancing cognitive training through aerobic exercise after a first schizophrenia episode: theoretical conception and pilot study. Schizophr Bull. 2016;42(suppl 1):S44-S52.

87. Bertelsen M, Jeppesen P, Petersen L, et al. Five-year follow-up of a randomized multicenter trial of intensive early intervention vs standard treatment for patients with a first episode of psychotic illness: the OPUS trial. Arch Gen Psychiatry. 2008;65(7):762-771.

88. Secher RG, Hjorthøj CR, Austin SF, et al. Ten-year follow-up of the OPUS specialized early intervention trial for patients with a first episode of psychosis. Schizophr Bull. 2015;41(3):617-626.

89. Insel TR. Translating scientific opportunity into public health impact: a strategic plan for research on mental illness. Arch Gen Psychiatry. 2009;66(2):123-133.

90. Jain KK. Textbook of Personalized Medicine. New York, NY: Springer; 2009.

91. Sanderson C, Clarkin JF. Further use of the NEO-PI-R personality dimensions in differential treatment planning. In: Costa PT, Widiger TA, editors. Personality Disorders and the Five-Factor Model of Personality. 2nd ed. Washington, DC: American Psychological Association; 2002:351-375.

92. Davidson L, McGlashan TH. The varied outcomes of schizophrenia. Can J Psychiatry. 1997;42(1):34-43.

93. Carpenter Jr WT, Kirkpatrick B. The heterogeneity of the long-term course of schizophrenia. Schizophr Bull. 1988;14(4):645.

94. Tsuang MT, Lyons MJ, Faraone SV. Heterogeneity of schizophrenia. Conceptual models and analytic strategies. Br J Psychiatry. 1990;156(1):17-26.

95. Zhang JP, Robinson DG, Gallego JA, et al. Association of a schizophrenia risk variant at the DRD2 locus with antipsychotic treatment response in first-episode psychosis. Schizoph Bull. 2015;41(6):1248-1255.

96. Bosia M, Bechi M, Marino E, et al. Influence of catechol-O-methyltransferase Val 158 Met polymorphism on neuropsychological and functional outcomes of classical rehabilitation and cognitive remediation in schizophrenia. Neurosci Lett. 2007;417(3):271-274.

97. Bosia M, Zanoletti A, Spangaro M, et al. Factors affecting cognitive remediation response in schizophrenia: the role of COMT gene and antipsychotic treatment. Psychiatry Res. 2014;217(1):9-14.

98. Greenwood K, Hung C-F, Tropeano M, McGuffin P, Wykes T. No association between the catechol-O-methyltransferase (COMT) val158met polymorphism and cognitive improvement following cognitive remediation therapy (CRT) in schizophrenia. Neurosci Lett. 2011;496(2):65-69.

99. Breitborde NJK, Maple AM, Bell EK, et al. Activity-regulated cytoskeleton-associated protein predicts response to cognitive remediation among individuals with first-episode psychosis. Schizophr Res. Epub 2016 Dec 15.

100. Hulbert CA, Jackson HJ, McGorry PD. Relationship between personality and course and outcome in early psychosis: a review of the literature. Clin Psychol Rev. 1996;16(8):707-727.

101. Brackett MA, Rivers SE, Shiffman S, Lerner N, Salovey P. Relating emotional abilities to social functioning: a comparison of self-report and performance measures of emotional intelligence. J Pers Soc Psychol. 2006;91(4):780-795.

102. Bell EK, Breitborde NJK. Personality-informed psychosis interventions: Using personality characteristics to inform psychosocial interventions for psychotic disorders. In: Columbus AM, editor. Advances in Psychology Research. Vol 105. Hauppage, NY: Nova Science Publishers; 2015:21-40.

103. Kessler RC, Amminger GP, Aguilar-Gaxiola S, Alonso J, Lee S, Ustun TB. Age of onset of mental disorders: a review of recent literature. Curr Opin Psychiatry. 2007;20(4):359-364.
104. Arnett JJ. Emerging adulthood: a theory of development from the late teens through the twenties. Am Psychol. 2000;55(5):469-480.

105. McGorry P, Bates T, Birchwood M. Designing youth mental health services for the 21st century: examples from Australia, Ireland and the UK. Br J Psychiatry Suppl. 2013;54:s30-35.

106. McGorry PD, Goldstone SD, Parker AG, Rickwood DJ, Hickie IB. Cultures for mental health care of young people: an Australian blueprint for reform. Lancet Psychiatry. 2014;1(7):559-568.

107. Patulny R, Muir K, Powell A, Flaxman S, Oprea I. Are we reaching them yet? Service access patterns among attendees at the headspace youth mental health initiative. Child and Adolesc Ment Health. 2013;18(2):95-102.

108. Rickwood DJ, Telford NR, Parker AG, Tanti CJ, McGorry PD. Headspace - Australia's innovation in youth mental health: who are the clients and why are they presenting. Med J Aust. 2014;200(2): 108-111.

109. Brunette M, Rotondi A, Ben-Zeev D, et al. Coordinated technologydelivered treatment to prevent rehospitalization in schizophrenia: a novel model of care. Psychiatr Serv. 2016;67(4):444-447.

110. Niendam T, Iosif AM, Tully LM, Burch K, Carter C. Preliminary longitudinal study examining the clinical correlates of medication adherence assessed via a mobile health application in early psychosis care. Neuropsychopharmacology. 2015;40:S576.

111. Breitborde N, Dawley D, Bell EK, Vanuk JR, Allen J, Lane RD. A personalized paced-breathing intervention to increase heart rate variability among individuals with first-episode psychosis following stress exposure. Schizophr Res. 2015;169(1-3):496-497.

112. Torous J, Chan S, Yellowlees P, Boland R. To use or not? Evaluating ASPECTS of smartphone apps and mobile technology for clinical care in psychiatry. J Clin Psychiatry. 2016;77(6):e734-e738.

113. Rainie L, Wellman B. Networked: The New Social Operating System. Cambridge, MA: MIT Press; 2012.

114. Abdel-Baki A, Lal S, D-Charron O, Stip E, Kara N. Understanding access and use of technology among youth with first-episode psychosis to inform the development of technology-enabled therapeutic interventions. Early Interv Psychiatry. 2017;11(1):72-76.

115. Lal S, Dell'Elce J, Malla AK. Technology access and use among young adults with a first episode of psychosis. Psychiatr Serv. 2015; 66(7):764-765

116. Depp CA, Kim DH, Vergel de Dios L, Wang V, Ceglowski J. A pilot study of mood ratings captured by mobile phone versus paper-and-pencil mood charts in bipolar disorder. J Dual Diagn. 2012;8(4):326-332.

117. Ben-Zeev D, Brenner C, Begale M, Duffecy J, Mohr D, Mueser K Feasibility, acceptability, and preliminary efficacy of a smartphone intervention for schizophrenia. Schizophr Bull. 2014;40(6):1244-1253.

118. Alvarez-Jimenez M, Bendall S, Lederman R, et al. On the HORYZON moderated online social therapy for long-term recovery in first episode psychosis. Schizophr Res. 2013;143(1):143-149.

119. Depp CA, Moore RC, Perivoliotis D, Granholm E. Technology to assess and support self-management in serious mental illness. Dialogues Clin Neurosci. 2016;18(2):171-183.

120. Firth J, Torous J. Smartphone apps for schizophrenia: a systematic review. JMIR Mhealth Uhealth. 2015;3(4):e102.

121. Guralnick MJ. Second generation research on the effectiveness of early intervention. Early Educ Dev. 1993;4(4):366-378.

122. Breitborde NJK, Srihari VH, Pollard JM, Addington DN, Woods SW. Mediators and moderators in early intervention research. Early Interv Psychiatry. 2010;4(2):143-152.

123. McGorry PD, Yung AR, Phillips LJ, et al. Randomized controlled trial of interventions designed to reduce the risk of progression to firstepisode psychosis in a clinical sample with subthreshold symptoms. Arch Gen Psychiatry. 2002;59(10):921-928.

124. McGorry PD, Yung AR, Phillips LJ. The "close-in" or ultra high-risk model: a safe and effective strategy for research and clinical intervention in prepsychotic mental disorder. Schizophr Bull. 2003;29(4) $771-790$. 


\section{Publish your work in this journal}

Psychology Research and Behavior Management is an international, peerreviewed, open access journal focusing on the science of psychology and its application in behavior management to develop improved outcomes in the clinical, educational, sports and business arenas. Specific topics covered in the journal include: Neuroscience, memory and decision making; Behavior modification and management; Clinical applications; Business and sports performance management; Social and developmental studies; Animal studies. The manuscript management system is completely online and includes a very quick and fair peer-review system, which is all easy to use. Visit http://www. dovepress.com/testimonials.php to read real quotes from published authors.

Submit your manuscript here: https://www.dovepress.com/psychology-research-and-behavior-management-journal 